\title{
Gênero e qualidade de vida percebida - estudo com professores da área de saúde
}

\author{
Gender and perceived quality of life \\ - research with professors from the health area
}

\author{
Elizabete Regina Araújo de Oliveira ${ }^{1}$ \\ Átala Lotti Garcia ${ }^{1}$ \\ Maria José Gomes ${ }^{2}$ \\ Telmo Oliveira Bittar ${ }^{3}$ \\ Antonio Carlos Pereira ${ }^{3}$
}

\footnotetext{
${ }^{1}$ Departamento de

Enfermagem, Centro

Biomédico, Universidade

Federal do Espirito Santo.

Av. Marechal Campos 1468,

Maruípe. 29060-270

Vitória ES.

elizabete_regina@hotmail.com

${ }^{2}$ Departamento de

Odontologia, Centro

Biomédico, Universidade

Federal do Espírito Santo

${ }^{3}$ Departamento de Saúde

Coletiva, Faculdade de

Odontologia de Piracicaba,

Universidade Estadual de

Campinas
}

\begin{abstract}
The rapid process of change in the global economy in recent years and the organization of labor have influenced gender relations in the teaching profession. These transformations have been disadvantageous for women, leaving them in a situation of occupational overload. The scope of this study was to analyze the working conditions of female teachers in higher education in the health education area in the city of Vitória, State Espirito Santo, and their implications on health and quality of life. This is qualitative research into data gathered from interviews upon which Bardin content analysis was also employed. This technique revealed three categories: leisure, rest and health; sense of loss of social and family interaction; and perceived quality of life. The results show that insufficient leisure time may lead to sleep disturbances predisposing the individual to psychic illness; overwork; significant alterations in labor organization compromising social and family interaction with repercussions on health and quality of life. The work performed by female professors in the health area contributes to the onset of illness, with pejorative effects on their family, love, social, environmental and professional lives, with consequent loss of quality of life.
\end{abstract}

Key words Gender, Quality of life, Students
Resumo O rápido processo de mudanças na economia global nos últimos anos e a organização do trabalho configuram as relações de gênero no trabalho docente. Essas transformações têm favorecido a situação desvantajosa da mulher, deixando-a em uma situação de sobrecarga ocupacional. Foram analisadas as condições de trabalho de Professoras do ensino superior da área da saúde em Vitória, no Estado do Espírito Santo, e suas implicações sobre a saúde e qualidade de vida. Trata-se de uma pesquisa de abordagem qualitativa. A coleta de dados foi realizada através de entrevistas e para a análise empregou-se a análise de conteúdo de Bardin, possibilitando a abordagem de três categorias: lazer, descanso e saúde; sentimentos de perda da interação social e familiar; $e$ qualidade de vida percebida. Os resultados apresentam relatos relacionados à ausência de lazer com consequentes distúrbios do sono favorecendo doenças psíquicas; excesso de trabalho; alterações significativas na forma de organização do mesmo, comprometimento da interação social e familiar, com influência sobre a saúde e a qualidade de vida. O trabalho executado pelas professoras da área da saúde contribui para o desenvolvimento do processo de adoecimento, com influência sobre a sua vida familiar, amorosa, social, ambiental e profissional, com perda da qualidade de vida.

Palavras-chave Gênero, Qualidade de vida, Docentes 


\section{Introdução}

O aumento do número de mulheres integradas ao mercado de trabalho retrata um fato considerado irreversível, uma vez que a proporção da população feminina na faixa etária dos 15 aos 64 anos, inserida no mercado de trabalho nos países desenvolvidos aumentou significativamente nos últimos anos ${ }^{1}$.

Este aumento, entretanto, não significou uma diminuição proporcional dos afazeres domésticos, pois as mulheres ainda continuam dedicando muito tempo a estas atividades. Essa responsabilidade construída culturalmente tem sido utilizada como argumento para a precarização do trabalho feminino, pois a ela somam-se os encargos do trabalho dentro e fora do $\mathrm{lar}^{2}$. Segundo Hirata ${ }^{3}$, a crise e a globalização trouxeram a exacerbação de certas formas de desigualdade, as mulheres continuam maciçamente a trabalhar e a cuidar da casa, o que poderá dificultar sua ascensão profissional.

Homens e mulheres desempenham diferentes papéis sociais e tendem a ter diferentes necessidades $^{4}$. As mulheres, contudo, necessitam adaptar suas responsabilidades domésticas e familiares às funções profissionais. Tal fato, quando realizado sob condições adversas de pressão social, afetam diretamente a sua saúde física e mental $^{5,6}$. Para Tosta ${ }^{7}$ o equilíbrio mental é o que carrega e direciona todos os impulsos da vida. Os quais, quando acometidos pela peste emocional não são liberados adequadamente, acarretando em relacionamentos incompatíveis e em incursões nas doenças psíquicas do trabalho: neuroses, depressões, fobias, stress e até suicídio.

A imprevisibilidade que atinge a economia e a vida das populações, de diferentes regiões e países do mundo, gera insegurança e mal-estar da população economicamente ativa. Estas mudanças, fontes constante de estresse, são provenientes do acumulo de estímulos advindos de diferentes fontes, tanto profissional quanto social, e acabam por atingir o plano da subjetividade que é vivenciada com a presença constante da incerteza.

Essa dúvida passa a permear a vida afetiva, dentro e fora do trabalho, assumindo importante papel na dinâmica em que se estabelecem alterações da sociabilidade e da saúde mental, repercutindo de forma contundente na qualidade de vida e na saúde dos trabalhadores ${ }^{8}$. No caso das mulheres trabalhadoras, acentuam-se quando elas são as responsáveis pela maior renda familiar ou quando são mães que cuidam dos filhos sem ajuda paterna.
Em decorrência destes fatores, destaca-se o adoecimento das docentes, altamente prevalente no meio acadêmico. Dados levantados pelo Sindicato dos Professores no Estado do Espírito Santo apontam que o número de licenças médicas no período de 2000 a 2005, de docentes da área da saúde, em Instituições de Ensino Superior (IES) apresentou um aumento de $18 \%{ }^{9}$.

São profissionais que acumulam algumas vezes três jornadas de trabalho: como profissional de saúde, de educação e como dona de casa. Essa situação desfavorável repercute em sua saúde podendo desencadear um processo de estresse, além de outros problemas psicossomáti$\cos ^{10,11}$. Para Dejours ${ }^{12}$ as exigências do trabalho e da vida são uma ameaça ao próprio trabalhador, gerando riscos de sofrimento.

A utilização do conceito de qualidade de vida no trabalho está em consonância com um movimento dentro das ciências humanas e das biológicas, que procura valorizar parâmetros mais amplos que o controle de sintomas, a diminuição da mortalidade ou o aumento da expectativa de vida e proporcionar um grau de satisfação do individuo com a instituição e com sua vida e oferecer condições ambientais gerais que contribuam para a promoção da saúde do trabalhador ${ }^{13,14}$.

A saúde do trabalhador é mantida quando as exigências do trabalho e do ambiente não ultrapassam as suas limitações energéticas e cognitivas. A qualidade de vida (QV) nunca é uma mera consequência, porém existem múltiplos fatores que estão relacionados e envolvidos com a capacidade funcional, o nível socioeconômico e a satisfação.

Assim, surge o termo qualidade de vida percebida (QVP), que é definida pela OMS: “... a percepção do individuo de sua proteção na vida, no contexto da cultura e sistema de valores nos quais ele vive em relação aos seus objetivos, expectativas, padrões e preocupações" ${ }^{15,16}$.

O objetivo deste estudo, portanto, é avaliar as condições de trabalho sobre a saúde e qualidade de vida percebida de mulheres docentes do ensino superior na área da saúde, da cidade de Vitória - ES.

\section{Metodologia}

Trata-se de um estudo qualitativo descritivo do tipo exploratório, realizado em duas instituições de ensino superior, uma particular e outra pública, da cidade de Vitória - ES. Este estudo foi aprovado pelo Comitê de Ética em Pesquisa, da Universidade Federal do Espírito Santo. 
A amostra foi constituída por 19 mulheres docentes das instituições de ensino superior estudadas, que concordaram em participar voluntariamente e assinaram o termo de consentimento livre e esclarecido. Foi constituída de 14 mulheres casadas com filhos e 5 solteiras, com idade de 30 a 50 anos. O instrumento de coleta de dados foi um questionário com uma questão aberta para o desenvolvimento da seguinte questão: "Você considera sua vida em termos de dedicação a família, lazer e outros, equilibrada com o trabalho? Quais comentários gostaria de fazer?”.

A análise dos dados foi realizada através da técnica de análise de conteúdo de Bardin ${ }^{17}$, definida como conjunto de técnicas de análise das comunicações visando obter, por procedimentos sistemáticos e objetivos de descrição do conteúdo das mensagens, indicadores que permitam a inferência de conhecimentos relativos às condições de produção/recepção destas mensagens.

Nesse estudo, a análise de conteúdo proposta sob a ótica de Bardin ${ }^{17}$ realizou-se por meio dos seguintes passos: transcrição das entrevistas, leitura do texto e verificação dos termos semelhantes, unidades de análise e agrupamento em categorias gerais, extraindo as seguintes categorias: lazer, descanso e saúde; sentimentos de perda da interação social e familiar; e qualidade de vida percebida. As falas receberam uma codificação em ordem crescente (D1; D2; D3...) em atendimento aos aspectos éticos e legais.

\section{Resultados e discussão}

Os resultados são apresentados por categorizações extraídas dos discursos:

\section{Categoria 1. Lazer, Descanso e Saúde}

A categoria docente é uma das mais expostas a ambientes conflituosos e de alta exigência de trabalho, tais como tarefas extraclasse, reuniões e atividades adicionais, problemas com alunos que chegam até a ameaças verbais e físicas, pressão do tempo, etc. Esta situação estressante leva a repercussões na saúde física e mental e no desempenho profissional dos professores ${ }^{2,18}$. O impacto dos fatores estressantes sobre profissões que requerem condições de trabalho específicas, com grau elevado de relação com o público, como a do professor, tem sido estudado em outros países sob a denominação de Síndrome de Burned Out, ou Burnout que, no Brasil, recebeu a denominação de Síndrome do Esgotamento Profissional ${ }^{12}$.
A síndrome do esgotamento profissional pode ser exacerbada pela falta de lazer e de descanso. Observa-se no grupo pesquisado que o excesso de trabalho, seguido por dificuldade de planejamento da vida pessoal/familiar, afetou o lazer conforme destacado nos discursos abaixo:

D1 “- Não me lembro, há muitos anos, de me sentir de férias realmente, desligar de tudo, mesmo que esteja de férias da universidade, tem sempre coisas pendentes, nunca conseguimos atender todas as demandas."

D2 “- Aonde vamos sempre carregamos material de trabalho..."

D3 “- Da vez que tirei férias quando retornei me vi louca com o acúmulo de serviço, e não consegui ir a congressos importantes na época..."

D7 “- Estamos o tempo todo conectados ..."

D8 “- Estamos ligadas, preocupadas, as sobrecargas são grandes de cumprimento de demandas sem fim..."

D9 “- São tantos trabalhos extras...”

Ressalta-se que muitas dessas mulheres assumem outras jornadas de trabalho além da docência e dos trabalhos domésticos, trabalhando também na assistência, em consultório, hospital ou unidade de saúde.

D10 “- Meu lazer é ler de vez em quando um jornal e ver TV, só quando recebo visitas de fora do Estado, familiares, é que me obrigo a sair, mas depois de uns dias torna-se um peso."

D11 "- Eu tocava e pintava... mas isso faz muito tempo...”

D13 "- Meu lazer tem sido ir ao supermercado, mas nem isso me dá prazer mais, me sinto explorada cada vez que entro num..."

Agregado à falta de lazer e de descanso observa-se uma sobrecarga de atividade cognitiva e o estresse consequente da corrida pela sobrevivência, ocorrendo alterações no sono e desordens psíquicas, o que afeta a saúde da docente, de acordo com as falas das entrevistadas. Segundo Souza e Reimão ${ }^{19}$ a insônia afeta a qualidade de vida geral de seus portadores. Quando a insônia é crônica, geralmente reflete distúrbios psicológicos e comportamentais.

D 16 “- Não é uma vida saudável, qualquer solicitação a mais é um sofrimento maior...”

D 17"- Tentamos provar pra nós mesmas que somos capazes de assumir tudo isso, mas o corpo cobra com juros, ficamos doentes e sem motivação pra nada."

Observa-se que os relatos corroboram com os obtidos por $\operatorname{Codo}^{10}$, quanto à presença de exaustão emocional nas docentes estudadas. Ressalta-se ainda a desvalorização profissional, bai- 
xa autoestima e ausência de resultados percebidos no trabalho desenvolvido.

Este potencial de trabalho da docente de saúde muitas vezes é desgastado por horas intensas de trabalho, o que poderia ser motivo de realização e de qualidade de vida passa a ser resultado de sofrimento e de doença.

Neves e Pedrosa ${ }^{2}$ afirmam que as transformações em curso no mundo do trabalho têm a peculiaridade de submeter aos seus critérios todos os setores e atividades. Desse modo, o setor público e o privado passam a ser objeto de uma série de processos modernizantes, desencadeando alterações significativas no equilíbrio das funções sistêmicas, orgânicas e psíquicas, que interfere com mais intensidade nas mulheres.

Os resultados obtidos neste estudo concordam com os de Neves e Pedrosa ${ }^{2}$, pois se observa que o nível de autoexigência mesclada à competição que se apresenta no meio acadêmico é grande. A globalização fez com que esta corrida pela informação deixasse as pessoas mais aceleradas em todos os sentidos.

Se antes, num quadro organizacional taylorista, seguir as regras era suficiente para um bom desempenho no trabalho, hoje, solicita-se iniciativa, envolvimento, criatividade e qualidade. Neste contexto, a organização fica submetida a certa vulnerabilidade na medida que, para funcionar com eficácia, depende da adesão dos trabalhadores ${ }^{20}$.

\section{Categoria 2. Sentimentos de perda da interação social e familiar}

Dentre os discursos colhidos, um aspecto a ser destacado é a rotina pré-estabelecida de trabalho. Nas escolas públicas e, principalmente, nas escolas particulares, onde não cumprem uma carga horária regular, a mudança de horários de aula, que acontece semestralmente, dificulta a vida social, a prática de atividades físicas e consequentemente, a estabilidade psicológica.

Dificilmente existe possibilidade de encontros entre as mesmas pessoas. Quando se começa a criar um vinculo, ele se desfaz no semestre seguinte. Com relação à continuidade destes vínculos fora do horário de trabalho, não se consegue disponibilizar tempo para encontrar com amigos, reduzindo seu círculo de amizade apenas aos familiares e vizinhos. Restringe-se assim o campo das interações sociais, necessário para uma vida saudável, desenvolvendo um sentimento de isolamento social.

D1 “- De um semestre para outro mudam as pessoas e acabamos por não termos apoio dos amigos, sentimos sozinhos... muitas vezes chego na sala dos professores e não conheço ninguém."

D2 "- Todos os amigos estão no mesmo esquema, então não tenho vida social..."

D4 "- É basicamente trabalhar, sem um contexto social, vira tudo obrigação... prefiro dormir."

A exclusão das docentes das atividades sociais dificulta sua integração na vida da comunidade, ela se encontra sozinha sem os apoios sociais necessários, com pouco apoio institucional ou profissional, mergulhada em um universo de demandas e exigências. Intensificando sempre o processo negativo do trabalho ${ }^{21}$.

De acordo com os discursos podemos visualizar como a mulher ainda carrega o peso cultural de ser responsável pela harmonia e organização no lar mesmo tendo a maioria das horas de trabalho fora de casa.

D12 “- Meu filho vive me questionando por que eu não tenho uma vida normal igual às outras mães, nunca tenho tempo para ficar tranquila com ele, e estou sempre dizendo para se apressar. Meu marido se cansou de escutar não posso, não tenho tempo".

Observa-se que as mulheres têm jornada de trabalho ilimitada, na qual associada ao trabalho formal encontra-se o trabalho familiar e doméstico. Muitas vezes são chefes de família, o que representa esforço excessivo contribuindo para uma má qualidade de vida. Quando se refere à mulher, o tempo de trabalho parece ser elemento destacável para determinar a percepção da qualidade de vida.

D18 “- Na idade produtiva da mulher... ela tem oportunidade de subir na carreira, mas fica dividida entre ter filhos e dedicar-se à vida doméstica."

D 9 “- Com a mudança do papel da mulher, a gente ganhou liberdade de pensamento e ação, mas o mundo continua com os mesmos preconceitos... é um preço alto que a mulher tem que pagar... cuidar de toda organização da casa e dos filhos e ajudar a sustentar a casa, quando se é sozinha nem se fala, tem que dar conta de tudo, sem contar com ninguém... tudo isto reflete no plano físico e emocional."

D17 “- Tentamos provar pra nós mesmas que somos capazes de assumir tudo isso, mas o corpo cobra com juros, ficamos doentes e sem motivação pra nada."

D1 “- Tá tudo errado..."

D2 “- Antes eu podia tentar fazer algo no horário de almoço, mas agora com filho pequeno, não consigo tempo para mim."

$O$ conceito de relações sociais de gênero contribuiu para o avanço na compreensão da com- 
plexidade da articulação trabalho/gênero. Desta forma, o fundamento social dessas diferenças aponta no sentido de interpretá-las como desigualdades, enraizadas nas concepções e práticas culturais do que se define como "ser homem" e "ser mulher" em cada contexto particular, e por isso, passíveis de diferentes configurações e conteúdos concretos e simbólicos ${ }^{22}$.

As diferenças de oportunidades entre homem e mulher ainda são grandes, as leis parecem favorecer a mulher, mas na prática, o homem tem mais "direitos" do ponto de vista cultural e social. O homem pode descansar e desfrutar do lazer enquanto a mulher precisa dar conta dos afazeres domésticos e cuidar dos filhos no período que deveria ser reservado para descanso. Segundo Hirata ${ }^{3}$, há ainda um fenômeno importante identificado: $\mathrm{o}$ aumento do número de mulheres chefes de família, sobretudo por conta de mudanças no padrão das relações entre homens e mulheres, com o aumento do número de separações e divórcios. No Brasil, as mães de famílias monoparentais chegam hoje a $25 \%$. Na União Europeia, esse porcentual é de $14 \%$, o que significa que elas estão à frente de 7 milhões de famílias.

\section{Categoria 3. Qualidade de vida percebida}

A qualidade de vida tem sido um tema bastante discutido na atualidade, sendo concebida pela World Health Organization (WHO $)^{23}$ como a percepção do indivíduo sobre sua posição na vida, no contexto da cultura e dos sistemas de valores nos quais vive, e em relação a seus objetivos, expectativas, padrões e preocupações. Esta definição da $\mathrm{WHO}^{23}$ destaca a visão de que a qualidade de vida é um termo subjetivo e multidimensional, que inclui tanto facetas positivas quanto negativas.

Segundo Wallande ${ }^{24}$, "Qualidade de Vida é a combinação de bem-estar objetivo e subjetivo em múltiplos domínios da vida, considerados importantes na cultura e na época do indivíduo e que estão de acordo com padrões universais de direitos humanos". Assim, pensar em QV permite uma reflexão sobre vários aspectos da vida, como o grau de satisfação, a felicidade e o bem-estar ${ }^{25}$.

Tanto a definição da $\mathrm{WHO}^{23}$ quanto a de Wallander ${ }^{24}$ são muito valiosas, pois tendo em vista a subjetividade do tema, buscam abranger suas múltiplas esferas, percepções e expectativas, correlacionando os domínios físico, social e mental do indivíduo.

Esta contextualização da qualidade de vida encontra-se expressa nas falas das docentes entrevistadas:
D1 “- Eu parto do princípio de que qualidade de vida é gozar de uma boa saúde, ter um bom relacionamento familiar, estar satisfeito com seu setor de trabalho, tirando a questão salarial."

D4 “- Desenvolver bem suas tarefas, ter um círculo de amizade razoável, ter um ritmo de vida normal."

D8 “- Não estou fazendo atividade física, alimentação está prejudicada, porque os medicamentos me dão sonolência, ansiedade e faz a necessidade de comer muito doce, e eu como professora de educação física me cobro muito por isso, estou numa fase que me desconheço, não consigo ser representativa do que é a minha vida, acabei de fazer o meu doutorado, estou com dificuldade de planejar, estou trazendo convidados, estou com dificuldades de estar levando sozinha, minha concentração esta baixa, eu tenho lapsos de memória, isto está me deixando muito ansiosa."

D12 “- Estou sempre doente, estou em processo de reclusão, fuga, evito contato, pela depressão."

D13 “- Sempre fui de resolver tudo em casa, desde os trabalhos femininos até os masculinos, agora estou me vendo doente e incapacitada de fazer alguma coisa. Hoje prá vir prá cá foi quase amarrada, só de pensar em entrar me dava um nó na garganta."

D15 "- Eu tenho tido um problema que eu não acho que seja só meu, é com a quantidade de trabalho, eu não dou conta, faço de tudo para cumprir com as demandas, mas não consigo e isto me causa um sentimento de frustração, de não reconhecimento do que estou fazendo, muito tempo que estou sentido esta pressão, a carga de trabalho é muito grande, muitas horas de trabalho, isso se conjuga com ... urgente."

Entende-se com estas falas que o modelo de trabalho a qual estão submetidas exige um excesso de trabalho extraclasse, através de correções e de planejamentos, e, principalmente, pela demanda por atualização e pela necessidade de titulação.

Acentua-se que a mulher além do trabalho formal cumpre o informal, com as tarefas domésticas e a dedicação à família, o que contribui para uma percepção negativa da qualidade de vida. Este mesmo perfil de queixas foi detectado em outros estudos com professores, realizados por Paranhos ${ }^{26}$ e Marchiori et al. ${ }^{27}$.

Observa-se neste estudo que o ser humano mesmo percebendo as insatisfações com o seu trabalho, adoecimento e baixa qualidade de vida, sustenta esta condição de sobrevivência, impos- 
ta pelo mundo globalizado. Este fato sugere que o ser humano usa estratégias defensivas de enfrentamento, desenvolvendo defesas que visam evitar a dor e o sofrimento ${ }^{7,28}$. Em acréscimo, Dejours ${ }^{12}$ ressalta a ocorrência de relacionamentos incompatíveis e incursões de doenças psíquicas do trabalho.

\section{Considerações finais}

O exercício da docência remete ao controle de questões pedagógicas executadas dentro de sala de aula. Entretanto, os resultados deste estudo, demonstram que as professoras não são poupa- das das demandas globais a que estão submetidas, como tarefas extraclasse, extensa jornada de trabalho, cumprimento de tarefa com prazo curto de tempo, múltiplos empregos e carga horária de sala de aula. O somatório destas demandas propicia o surgimento de efeitos sobre a saúde mental deste grupo ocupacional, sugerindo a necessidade de elaboração de um projeto de intervenção em saúde do trabalhador, para melhorar a condição de trabalho da docente na área da saúde, diminuindo o sofrimento psíquico a que estão expostas, melhorando o grau de satisfação na sua vida familiar, amorosa, social, ambiental e consequentemente em sua atividade profissional, contribuindo para uma melhor qualidade de vida.

\section{Colaboradores}

ERA Oliveira, AL Garcia, MJ Gomes, TO Bittar e AC Pereira participaram igualmente de todas as etapas de elaboração do artigo. 


\section{Referências}

1. Brito JC. Saúde, trabalho e modos sexuados de viver. Rio de Janeiro: Fiocruz; 1999.

2. Neves MA, Pedrosa CM. Gênero, flexibilidade e precarização: o trabalho a domicílio na indústria de confecções. Sociedade e Estado 2007; 22(1):11-34.

3. Hirata H. As Novas Fronteiras da Desigualdade Homens e Mulheres no Mercado de Trabalho. São Paulo: Senac; 2003.

4. Ludermir $A B$. Inserção produtiva, gênero e saúde mental. Cad Saude Publica 2000; 16(3):647-659.

5. Bruschini C. Mulher, casa e família: Cotidiano nas camadas médias paulistanas. São Paulo: Fundação Carlos Chagas; 1990.

6. Giatti L, Barretos SM. Trabalho feminino e saúde na terceira idade. Cien Saude Colet 2002; 7(4):825-839.

7. Tosta F. Psicologia do trabalho e a peste emocional. Psicologia.pt [periódico na Internet]. 2007 [acessado 2010 abr 29]. Disponível em: www.psicologia.pt

8. Seligmann-Silva E. Desemprego e psicopatologia da recessão. In: Borges LH, Moulin MGB, Araújo MD, organizadores. Organização do trabalho e saúde: Múltiplas Relações. Vitória: EDUFES, 2001.p. 219-254.

9. Heckert AL, Aragão E, Barros MEB, Oliveira S. A dimensão coletiva da saúde: uma análise das articulações entre gestão administrativa-saúde dos docentes, a experiência de Vitória. In: Brito JC, Barros MEB, Neves MY, Athayde M, organizadores. Trabalhar na escola? Só inventando o prazer. Rio de Janeiro: Editora IPUB/CUCA; 2001.

10. Codo W. Educação: carinho e trabalho. Petrópolis: Editora Vozes; 1999.

11. Tamayo MR, Tróccoli BT. Burnout no trabalho. In: Mendes AM, Borges LO, Ferreira MC, organizadores. Trabalho em transição, saúde em risco. Brasilia: Editora Universidade de Brasília; 2002.

12. Dejours C. A loucura do trabalho: estudo de Psicopatologia do Trabalho. São Paulo: Cortez; 1998.

13. Albuquerque LG, França ACL. Estratégias de recursos humanos e gestão da qualidade de vida no trabalho: o stress e a expansão do conceito de qualidade total. Revista de Administração 1998; 33(2):40-51.

14. Fleck MPA, Leal OF, Louzada S, Xavier M, Chachamovich E, Vieira G, Santos L, Pinzon V. Desenvolvimento da versão em português do instrumento de avaliação de qualidade de vida da OMS (WHOQOL-100). Rev. Bras. Psiquiatr. 1999; 21(1):19-28.

15. Dantas RAS, Sawada NO, Malerbo MB. Pesquisa sobre qualidade de vida: Revisão da produção cientifica das universidades do Estado de São Paulo. Rev. Latino-am. Enfermagem 2003; 11(4)532-538.

16. Minayo MCS, Hartz ZMA, Buss PM. Qualidade de vida e saúde: um debate necessário. Cien Saude Colet 2000; 5(1):7-18.
17. Bardin L. Análise de Conteúdo. Lisboa: Edições 70; 1977.

18. Instituto Brasileiro de Geografia e Estatística (IBGE). Mulher no mercado de emprego [CD-ROM]. Rio de Janeiro: Instituto Brasileiro de Geografia e Estatística (IBGE); 2003.

19. Souza JC, Reimão R. Epidemiologia da insônia. Psicol Estud 2004; 9(1):3-7.

20. Kinker FE. Trabalho como produção de vida. Rev. Ter. Ocup. Univ. São Paulo 1997; 8(1):42-48.

21. Martínez D, Valles I, Kohen J. Salud y trabajo docente: Tramas do malestar en la escuela. Buenos Aires: Ed Kapelusz; 1997.

22. Holzmann L. Notas sobre as condições da mão-deobra feminina frente às inovações tecnológicas. Sociologias 2000; 4(jul/dez):258-273.

23. World Health Organization (WHO). Physical status: the use and interpretation of anthropometry. Technical Report Series 854. Geneva: World Health Organization (WHO); 1995.

24. Wallander JL. Theory driven research in pediatric psychology: a little bit on why and how. J. Pediatr Psychol 1992; 17(5):521-535.

25. Barreire SG, Oliveira OA, Kazama W, Kimura M, Santos VLCG. Qualidade de vida de crianças ostomizadas na ótica das crianças e das mães. J. Pediatr 2003; 79(1):55-62.

26. Parranhos I. Interface entre Trabalho Docente e Saúde, dos Professores da Universidade Estadual de Feira de Santana [dissertação]. Feira de Santana (BA): Universidade Estadual de Feira de Santana; 2001.

27. Marchiori F, Barros MEB, Oliveira SP. Atividade de trabalho e saúde dos/as professores: o programa de formação como estratégia de intervenção nas escolas. Revista Trabalho, educação e saúde 2005; 3(1):143170.

28. Boa-Sorte N, Neri LA, Leite MEQ, Brito SM, Meirelles AR, Luduvice FBS, Santos JP, Viveiros MR, Ribeiro-Júnior HC. Percepção maternal e autopercepção do estado nutricional de crianças e adolescentes de escolas privadas. J. Pediatr 2007; 83(4):349-356.

Artigo apresentado em 23/03/2010

Aprovado em 10/04/2010

Versão final apresentada em 03/05/2010 